\title{
Research on Independent Learning Mode under the Background of Internet Plus
}

\author{
Bo Han \\ College of Civil and Commercial Law \\ Shandong University of Political Science and Law \\ Jinan, Shandong, China
}

\begin{abstract}
Researches on independent learning have been going through a long time at home and abroad, however, most of them are following the way used for formal learning such as courses, classroom and so on, which lies in a technical environment relatively weak and closed. Today, the highly developed Internet technology has brought the educational circles a brand-new proposition, namely under the background of knowledge economy and lifelong learning, facing a developing Internet environment that is highly socialized, personalized and open, how does an individual to achieve the independent learning? Within the theme, the core problem hidden inside is the realization of Internet's support to the independent learning and new needs for changes of independent learning mode. Currently, what fit in with the development the most and reflect the development trend of the technological environment in the future are the independent learning under the background of Internet, therefore, this article will be devoted to studying the Internet-based independent learning models.
\end{abstract}

\section{Keywords-Internet; independent learning; mode}

\section{INTRODUCTION}

Nowadays, college students have been in an obvious need of diversified independent learning, yet the teaching programs in colleges and universities are unable to meet it. Therefore, to find a way to meet this need has become a problem urgent to be solved for the current higher education. Going with the movement of open educational resources around the world, higher education quality course projects, Internet education run by enterprises and the Internet have become resource platforms to meet the needs of college students in the diversified independent learning in China. Technical resources have their value realized in application. How to make full use the quality resources to meet the needs of college students in diversified independent learning will have a positive practical significance to improve the quality of personnel training and prevent the waste of resources. To train students to be independent is one of the important goals of college teaching in the new era, besides, to train the students' abilities of independent learning is just fitting with the trend where international educational circles are focused

This article is a medium-stage achievement of the Research on Independent Learning Mode under the Background of Internet Plus in the Key Teaching Reform Program of Shandong University of Political Science and Law (Program No: 2016JYA003), held by Chen Lijuan on the students' abilities of innovation, learning modes and key points transfer. Edgar Faure pointed out in the article "Learning to survive": "The illiterates in the future are no longer those who are unable to read but those who fail on how to learn." Since the 1990s, most countries around the world have taken training students to be independent and capable of lifelong learning as an important educational goal. The college education should keep people-oriented and have individual potentials developed, train students' abilities of application and comprehensive cultural quality, especially the teaching shall be converted to the individual and active learning so as to enhance the students' independence, and the independent learning is an important part for the teaching reform in colleges. With the advancement of teaching reform in colleges, more and more colleges have started to invest heavily to establish independent learning center, develop independent learning system, create the Internet-based independent learning platform so as to provide college students with sound material conditions in order for the independent learning. But the monitoring and management over the independent learning are seriously poor, and most of the independent learning modes and activities are going in formality, achieving little effect in practice. Therefore, it needs further strengthen the studies on theories and practice relative to the independent learning, especially actively explore the characteristics of Internet-base independent learning, psychological mechanism, theoretical basis and influential factors of independent learning, and build an Internet-based multidimensional monitoring system for the independent learning, instruct, supervise and manage the independent learning of college students, which will help the students form good habits in learning, enhance the students' awareness of independent learning, make good use of the independent learning strategies and improve the abilities of independent learning so as to the realize teaching goals in colleges.

\section{SUPPORT OF THE INTERNET TO THE INDEPENDENT LEARNING OF COLLEGE STUDENTS}

\section{A. Online Resources Offer A Great Number of Data for the Independent Learning}

During the independent learning that college students conduct according to the characteristics and interests of their own, teachers give little instruction and organization, and the 
dependency of students on teachers in knowledge is reduced, here the roles of resources for learning look much more important, if there are no appropriate resources for learning, the independent learning will become hard to realize like dead water, computer networks make it available to share all resources between users, the advantages are overwhelming for any other information or media tools.

\section{B. The Internet Brings Wide Interactive Space for Independent Learning}

Social constructivism held the opinion that learning is first of all a course to enter the culture of a community of practice. Learning refers to a course to make senses via communication and coordination with others on the basis of the knowledge that he or she has owned. Students can complete the sense-making only with the assistance or communication from others, yet currently during the class teaching, teachers are limited in energy and time, who are unable to made close trace and instruction on the learning of every student, as such, the individual learning of students become a leaning alone, they often encounter problems and difficulties that are unable to solve, at last they even give up to further learning. The Internet brings a great assistance to the students, actually the network itself is a huge platform for exchange, and students may communicate with those in the same camp at home and even the world in order for assistance, which will be of great importance for the independent learning of students.

\section{The Internet Offers Platforms Supporting the Learning Activities}

In order to promote the students' independent learning and help them achieve the purpose of deep learning, during the teaching, teaching activities in diverse forms will be developed, which often require the support of rich interactive environment and information. The high connection and diversity of resources in the form just meet this requirement. Therefore, the Internet is thought to provide platforms in support of the teaching activities.

\section{STATUS QUO AND DEFECT OF INDEPENDENT LEARNING OF COLLEGE STUDENTS UNDER THE BACKGROUND OF THE INTERNET PLUS}

The problems that exist in the Internet-based independent learning of college students can be analyzed from two points, that is, internal factors and external factors. The internal factors refer to the problems of college students themselves, the external factors refer to Internet-based resources and atmosphere for independent learning as well teachers' instruction. The internal factors play a decisive role in the development of things and the external factors influence the progress of things via the internal factors, which means that during the Internet-based independent learning, the factors of college students themselves directly determine the efficiency of the Internet-based independent learning, and other factors such as the environment, material conditions, teachers and so on work on the efficiency of the Internet-based independent learning via the students. The overall analysis of internal and external factors will make it better to correctly understand the factors which restrict the Internet-based independent learning.

\section{A. Problems Existing in College Students}

First, the Internet-based independent learning time is relatively short. First of all, we need to know that the Internet-based independent learning has become a common phenomenon. In addition to usual class time and normal rest time, college students have more spare time, plus, the popularity of computers has made it easy for the Internet access in colleges, the Internet is accessible and very convenient. The Internet is more than a channel to acquire information, to which, students have shown great enthusiasm, highly addicted to it. The Internet-based independent learning is accompanied by the use of the Internet, Internet is used by students mainly for independent learning and entertainment, among college students, almost everyone may more or less make use of the Internet for independent learning, seen from these, the Internet-based independent learning has been an important way for college students to acquire knowledge, and it can be said the Internet -based independent learning is existing widely. Second, we have to acknowledge that the wide existence of the Internet-based independent learning is shown by the number of number of students, the use of the Internet by college students is thought good, however, in the current life, most of college students are found still using the Internet for entertainment, where they are seeking for spiritual pleasures and satisfaction, maybe, the entertainment can also pass information and offer knowledge, yet it targets something else. Relevant survey data also show that the Internet-based independent learning time is far lower than the surfing time, and there is still a large space to increase the proportion.

Second, internal factors are fundamental drives for the development of things, yet within the drives for the Internetbased independent learning of college students, more are sourced from external factors but not the drives of their own. Reasons for external drives are the pressure outside to stimulate the students for independent learning; reasons for internal drives are the needs of pursuing development to stimulate the students for independent learning; Among college students, interests and hobbies have a great significance to instruct the independent learning of individuals, and the contents of the Internet-based independent learning of most students are based on what they are interested in. In addition to this point, the students who are active to pursue the independent learning at heart occupy a lower proportion, and most hold no the concept "to live to learn" but are forced by the classroom tasks designated by teachers to start the Internet-based learning, and the inherent drives are seriously lower.

Third, during the Internet-based independent learning, there are almost no interaction between students and others, which ignores the importance of communication between people, while the social constructivism stressed that learning is a social activity that requires mutual cooperation and interaction. It was said in ancient time that one of two or more persons must be much wiser than I somewhere. The ability of an individual is limited, especially in the modern 
society, the labor is divided finely, if someone can excel in what he or she has learned, that will be thought uneasy. If he or she is required to be competent in all aspects, maybe, it will be impossible to achieve; even he or she excels in what he or she has learned, maybe, there will be someone else who can do it better. Therefore, the communication is expected to absorb others' strong points and overcome the weak points of their own, reduce the problems as possible as we can during the independent learning and avoid detours. Especially in the face of the Internet environment, there are no face-to-face interaction in traditional teaching, and the convenient interactive channels that the Internet offers may make up for many deficiencies to some degree, yet the importance of Internet communication is acknowledged clearly, and fails to attract adequate eyeballs. As a special group, college students have certain abilities of identification and basic social cognition, who are keeping cautious when communicating, how to well remove the ill feeling is more urgent and important than ever.

Fourth, the self control of college students over the Internet-based independent learning is lower generally, who are weak to resist the temptation of the Internet. On the Internet, resources for independent learning and entertainment are coexisting, and the students' attentions are in a greater challenge. And the independent learning changed to entertainment just needs a click. Relevant surveys show that the self control abilities of students are very poor, lured by the Internet resources, more than half of the students will completely abandon the existing tasks, $35 \%$ will suspend the tasks, and continue it after enjoying the entertainment.

\section{B. Problems Existing in the Internet-Based Independent Learning Environment}

Favorable external conditions are not only a prerequisite for students to achieve the Internet-based independent learning but also a booster to enhance the effect of independent learning and improve the independent learning environment. The study on the external factors influencing the independent learning may create convenient conditions for the Internet-based independent learning, and avoid the external factors from influencing the learning effect on the basis of improving the students' quality, so its importance goes well without saying. The construction of resources for learning is to explore the problems existing in the Internetbased independent learning from materials, which is the base for the independent learning, besides, the independent learning environment is a soft one, whose roles for the development of individuals shall not be ignored either. Here the independent learning environment mainly refers to the independent learning atmosphere.

First, surveys show that the atmosphere of students' independent learning is not strong enough. Seen from the routine independent learning, generally the students will spend most time in entertainment or other activities. The students in colleges shall not only acquire professional knowledge, but also participate in diverse extracurricular activities to color their life. In addition to professional quality acquired in colleges, the students need to strengthen comprehensive abilities of their own such as abilities $f$ communication, expression and so on so as to avoid being separated from the society. In addition to the training of abilities, the students spend most of their time in entertainment.

Second, though the Internet-based independent learning differs from the traditional environment, yet it is still in a high need of teachers. On the one hand, most students have already owned basic skills such as skilled operation of computer hardware and software, yet there are some students who have little access to computers, failing in normal operation. Especially many students are still unfamiliar with Word and Excel, and the education of basic skills relative to the Internet still need the participation and support of teachers. On the other hand, during the independent learning, the importance of teachers is no less than their roles in traditional independent learning. Starting from the drafting of independent learning plans, instruction on the independent learning to the feedback after completion of the independent learning, teachers play an extremely important role. For example, as far as the resources selected for the independent learning, most of the websites and blogs that students get access are recommended by teachers. For teachers have conducted a long term study on professional fields, owning rich social experience and capable of identifying the quality of resources, so no doubt what the teachers recommend will effectively shorten the time of students to search online, besides, high quality academic research results recommended to students make them access better resources so as to further improve the effect of independent learning. Teaching and learning, benefiting each other, can be combined for supporting each other.

\section{CONSTRUCTION OF INDEPENDENT LEARNING MODE FOR COLLEGE STUDENTS UNDER THE BACKGROUND OF INTERNET PLUS}

\section{A. Stimulate the Power for Independent Learning Online}

First, strengthen the goal-oriented education, set a concept of "To live to learn". The special environment where college students lie in makes the goal of independent learning stronger in utilitarian, though the utilitarian has many advantages, able to make sure of the goal, and full of power in the online independent learning, yet its shortcomings can not be ignored either. The utilitarianism tends to quick success, which will do hard to the realization of long-term goals, besides, the students will be caused impatient, forming a concept of learning for learning, the students' knowledge scope is relatively narrow, unable to digest quickly and use freely. Maybe, to conduct academic studies is for the academy, it is somewhat flawed, but the defects of utilitarianism are obvious. Therefore, to set a scientific philosophy in learning will have an important value.

Second, train the students' abilities of meta-cognition monitoring, establish a perfect system for evaluating the independent learning effect and avoid the adverse effect due to the focus on the exam-oriented results. Meta-cognitive monitoring is an important part of the meta-cognition, which plays an important role in training students' abilities of metacognition. During the online independent learning, the 
students are required to draft plans, skillfully control the implementation, evaluate the effect of the independent learning and adjust the strategies for learning. It requires that the evaluation mechanism shall be rational, currently the exam-oriented education system makes the results be the core and only standard to evaluate students, yet the irrational exam systems ignore the characteristics of students as individuals. The educational philosophy that results are all causes students to produce a psychological inversion against the independent learning online, which has inhibited the enthusiasm of students to develop the independent learning, so it is urgent to reform the exam-oriented education system. Actually it is completely feasible to adopt a diversified education system, where quality education and examoriented education are combined well with individual characteristics of students valued, it emphasizes both the fairness, equality and dealing case by case. For example, the evaluation of the Internet-based independent learning effect can be done online and also supported by traditional evaluation methods, during the evaluation, we should take into account the results and comprehensive abilities for evaluation and set up a perfect incentive mechanism.

Third, take measures and keep self confident for effect improvement. Self-efficacy is an important factor influencing the effect of independent learning, and selfconfidence is the most important factor in the self-efficacy. The lower effect of online independent learning generally will greatly affect the students' desires to persist in the independent learning. How to regain the self confidence and improve the effect has become an urgent need problem to solve. There are many factors that affect the self confidence, and we need to start with the students themselves and the society. On the one hand, the students should adjust the online independent learning strategies according to the conditions of their own and develop a rational online independent learning program; On the other hand, teachers should change the way that criticism predominated in the past, constantly encourage students, show more about their advantages and take measures appropriate to help them overcome shortcomings; in the meantime, colleges and the society should also provide students with favorable environment, avoiding the results first views and valuing the individualized education of students.

\section{B. Train the Abilities of Sound Self Monitoring}

In the face of the Internet situation, the significance of self monitoring has been going beyond the self monitoring in traditional environment. In addition to the factors of students themselves, the environmental factors are also outstanding.

First of all, students should fully understand the value of self monitoring and correctly handle the relations between independent learning and entertainment. In recent years, the theory of self-monitoring ability has attracted most eyeballs, which requires students to control the independent learning online, arrange the time properly, make full preparation for materials for learning, able to control the motive of independent learning online, exclude the factors influencing the independent learning so as to improve the learning efficiency. No doubt the self monitoring ability does not mean pure learning without entertainment. Scientific researches show that within the long term independent learning, appropriate entertainment may promote the efficiency of the independent learning. Generally the self monitoring abilities of college students are weak, it turns out that we should fully understand the importance of the independent learning. To train a good self monitoring ability is a necessity to achieve the independent learning online.

Second, combine self-monitoring and someone else's control. The training of self monitoring ability will need perseverance and patience, which can be achieved through progressive development, students can monitor each other, then make it last longer and longer. The self monitoring ability needs to the support of favorable external environment in order to make it work. The special environment in colleges determines that the students in the same dorms are highly influenced each other, how to form a good independent learning atmosphere in dorms has become a key problem. In this regard, teachers can make rational distribution according to the students' interests, needs and abilities relative to the independent learning. And those in the same dorms may set up online independent learning group for mutual supervision and improvement. Therefore, during the period for training of self monitoring ability, the roles of being monitored will become weak, the self monitoring shall be combined with the being monitored, the being monitored is the guide for independent learning, and the self monitoring is the ultimate goal for the independent learning.

Finally, the implementation of self monitoring also needs incentive measures. Though the self monitoring stresses the students' dominant roles, yet the incentive measures can promote students to develop the self monitoring abilities from outside. External measures include encouragement and punishment, the former will be advocated actively, and the latter will punish the behaviors against the self monitoring abilities, which is mandatory. After all, the incentive measures given here are not specifically aiming at the self monitoring abilities, but combined with the evaluation on the independent learning effect, which does not exist separately.

\section{Exert the Roles of Teachers in Online Independent Learning}

The online independent learning does not mean "learning alone", though it stresses the students' dominant roles, yet it doest not reject the teachers' participation. According to the social-cognitive learning theory and behaviorist theory, the environment may affect the online independent learning effect to some degree, and teachers play an important role in building a sound online independent learning environment, besides, the online independent learning raises higher requirements to teachers.

First of all, teachers should fully recognize the students' dominant roles in the online independent learning. Though some scholars point out that the teacher-centered and the student-centered are not completely opposed to each other, in the traditional education, the teacher-centered classroom can also improve the students' abilities of independent learning, 
and teachers are not arbitrary in teaching. It is true actually, even in the exam-oriented educational mode, teachers can also take some measures to stir the enthusiasm of students, though students are not completely passive to accept the knowledge, yet no doubt the teachers have a dominant role in the traditional learning, which are obvious, all curriculum plans are done according to the teachers' curriculum design, which do no good to inspiring innovation, instead, it may inhibit the students' awareness of independent learning. In the online independent learning, the statuses between teachers and students are interchanged, and the awareness of dominant roles of students will need teachers' assistance for development and improvement. It requires that teachers should change the traditional concepts of exam-oriented education in teaching, value the students' awareness of innovation and independence, guiding continuously students for online independent learning.

Second, teachers should fully know the importance of themselves in online independent learning. To change the traditional teacher-centered educational concept does not mean to directly reject the teachers' participation in teaching or free students in the independent learning. Teachers are necessary characters in the education. In the educational environment in China, both the traditional independent learning and online independent learning are social obviously, which makes people value and stress the relations between teachers and students and value the roles of other people in the society to achieve the common goal. Though the college education has been separated from the traditional spoon-feed education, yet the roles of teachers still need to be highly valued. Teachers are one of the best enlighteners for students. The influence of traditional concepts makes the relationship between teachers and students special. And teachers can make use of the special roles of their own to instruct the students in the online independent learning.

Third, the online independent learning raises higher requirements to teachers, who may make improvements from the following: First, after completion of routine teaching tasks, leave students some questions for thinking and encourage them to complete the task actively. Second, renovate the current educational mode, traditionally, teachers are monopolists of knowledge, having higher authority, however, in the era of the Internet, teachers' traditional position are changed, and the teaching contents should be focused on methods but not the knowledge dissemination. Third, establish a sound teacher-student relationship equal and friendly. Strengthen communication with students and do it through forum, tea party and so on, and take emotional education to communicate with students at heart so as to enhance the teacher - student emotion. In the traditional education, the inequality between teachers and students cause the students are humble, lack of innovation and even unable to adapt to the social development. The online independent learning is just to avoid the defects of the traditional education, no doubt the well-going teacherstudent relations will be of great significance for it.

\section{CONCLUSION}

With the development of Internet technologies, the teaching of higher education need to be further improved, and the independent learning is just a way for the teaching in the future, accordingly we should further renovate the existing teaching mode so as to meet the needs of the independent learning.

\section{REFERENCES}

[1] Jonathan, et al, translated by Ren Youqun, Li Yan, Shi Binfei, Learning to Solve Problems with Technology: A Constructivist Perspective (Edition II) [M] Beijing: Educational Science Publishing House, 2007

[2] Siemens G, translated by Zhan Qinglong, Knowing Knowledge [M] Shanghai: East China Normal University Press, 2009

[3] Han Lu, Researches on Strategies to Promote Students in Online Independent Learning [D] Hebei: Hebei University, 2010.

[4] He Qiaoyan, He Jisheng, Discussion on Concepts of Self-Directed Learning [J]. Journal of Hebei Normal University (Education Science Edition), 2009(2):33-36.

[5] Hua Weifen, Discussion on Learner Independence [J]. Journal of Shenzhen University (Humanities \& Social Sciences), 2002(2) :107112.

[6] A Kofod-Petersen, J Cassens (2006). Using Activity Theory to Model ContextAwareness. In Thomas R. Roth-Berghofer, Stefan Schulz,and David B. Leake,editors, Modeling and Retrieval of Context: MRC 2005,Revised Selected Papers,volume 3946 of LNCS (pp. 1-17). Edinburgh: Springer.

[7] Barnard L., Paton V. \& Lan W.. Online Self-Regulatory Learning Behaviors as a Mediator in the relationship between Online Course Perceptions with Achievemen. International Review of Research in Open and DistanceLearning ,2008.

[8] Li Guomin, Wang Xiaoxi, Shi Zhiyi, Discussion on Characteristics of Online Learning [J] TV University Teaching, 2001(6):1-7.

[9] Liu Chuanchuan, Analysis of Learning Style-based Online Complicated Learning Behaviors [D]. Gansu: Northwest Normal University, 2010

[10] Pang Weiguo, New Progress of Independent Learning Theories [J]. Journal of East China Normal University (Educational Sciences), 1999(3) : 68-74. 